\title{
Estudio de la fermentación láctica para la extracción de quitina a partir de desechos de crustáceos
}

\author{
E. Marcia, J. Malespín, M. Sánchez y M. Benavente* \\ Facultad de Ingeniería Química, Universidad Nacional de Ingeniería (UNI) \\ Avenida Universitaria, PO Box 5595, Managua, Nicaragua \\ E-mail: bena@kth.se
}

(recibido/received: 28-Enero-2011; aceptado/accepted: 3-Junio-2011)

\begin{abstract}
RESUMEN
La extracción de quitina a partir de desechos de crustáceos involucró la fermentación acido láctica para la desproteinización y desmineralización del caparazón de camarón, haciendo uso de suero de leche y sacarosa, como sustrato y fuente de carbono. El proceso de fermentación se llevo a cabo en un reactor vertical de vidrio Pyrex de 4 L por un período de 2 y 3 semanas a temperatura ambiente. Los resultados mostraron que aunque hubo una buena desproteinización y desmineralización, todavía el producto contenía restos de proteínas y pigmentos. Por ello, se hizo necesario aplicar un procedimiento químico con hidróxido de sodio e hipoclorito de sodio, para remover completamente las proteínas y los pigmentos de la estructura del caparazón. Al final del proceso se obtuvo una recuperación del 85 \%. La comparación de los espectros FT-IR de la quitina producida con una muestra de quitina comercial, mostró un porcentaje de correlación del 93-95 \%, lo que indica que la quitina obtenida utilizando el método combinado, tiene un alto grado de pureza.
\end{abstract}

Palabras claves: Caparazón de camarón; Quitina; Reactor vertical; Sacarosa; Suero de leche

\begin{abstract}
The extraction of chitin from crustacean waste involved the deproteinisation and demineralisation of crustacean shells using lactic acid fermentation with whey and sucrose as culture medium and carbon source, respectively. The fermentation process was carried out in a vertical Pyrex reactor of $4 \mathrm{~L}$ by 2 and 3 weeks at room temperature. The results showed that a good deproteinisation and demineralisation was obtained; however, the product still contained traces of proteins and pigments. Therefore, it was necessary to apply a chemical process with sodium hydroxide and sodium hypochlorite, to completely remove the proteins and pigments from the structure of crustacean shell. A recovery of $85 \%$ was obtained. The comparison of FT-IR spectra of chitin produced and a sample of commercial chitin showed a correlation rate of 93-95\%, indicating that chitin produced using the combined method has a high degree of purity.
\end{abstract}

Keywords: Chitin; Shrimp shell; Sucrose; Vertical reactor; Whey

*Autor para la correspondencia 


\section{INTRODUCCIÓN}

En Nicaragua existen 15 plantas procesadoras de camarón y langostino, de niveles y capacidad de proceso diferenciados, 8 de ellas localizadas en la zona del Pacifico (Hernández y Escorcia, 2009). Sin embargo, la industria acuícola produce una gran cantidad de desechos de crustáceos ya que estos constituyen el 40-50 \% aproximadamente del peso total $(\mathrm{Xu}$ et al., 2008). Estos desechos pueden repercutir negativamente en el medio ambiente y pueden generar un costo adicional para su deposición, reduciendo las utilidades del sistema de producción.

Estudios anteriores han demostrado que los desechos de langostinos y camarón pueden ser utilizados como materia prima para la producción de quitina y proteínas (Hernández y Escorcia, 2009). Así como también, para la obtención de otros valiosos subproductos para la industria, tales como quitosano y glucosamina (Pastor de Abram, 2004). Estos productos presentan numerosas aplicaciones en distintas áreas, principalmente en medicina, farmacia, remoción de metales pesados en el tratamiento de aguas naturales y efluentes industriales, cosméticos, industria alimenticia, etc. (Harish y Tharanathan, 2007).

El procesamiento químico para la extracción de estos productos implica el uso de altas concentraciones de ácidos y bases fuertes como el ácido clorhídrico y el hidróxido de sodio; así como también, grandes volúmenes de agua, lo que provoca contaminación ambiental debido a los desechos químicos (Xu et al., 2008). Además, por medio de esta técnica la recuperación, para el caso de la extracción de quitina a partir de cabeza de langostino, es muy baja ya que solamente se logra una recuperación del $58.6 \%$ (Hernández y Escorcia, 2009).

Como alternativa, el proceso microbiológico para la extracción de quitina por fermentación ácido láctica ha sido estudiado. Estos estudios han reportado tener mayores ventajas con respecto al tratamiento químico: no produce desechos tóxicos, mejor calidad del producto obtenido y disminución en los costos de producción (Xu et al., 2008; Carvalho et al., 2009).

Los estudios por fermentación láctica involucran el uso de bacterias del ácido láctico (Lactobacilo o Lactobacillus) para la desproteinización y descalcificación del material, obteniéndose quitina como producto final. Lactobacillus es un género de bacterias grampositivas no esporuladas, generalmente anaerobias que tienen la propiedad de producir ácido láctico por fermentación de la lactosa y otros azúcares (López et al., 2004). Algunas especies de lactobacillus son usadas industrialmente para la producción de yogur y otros alimentos fermentados.

Por otro lado, el suero de la leche, el cual es un gran contaminante de las aguas superficiales debido a su alta demanda bioquímica de oxigeno (DBO), puede ser utilizado como sustrato en las reacciones de fermentación láctica (Trujillo et $a l ., 1998)$. El suero de la leche es un líquido que se obtiene durante el proceso de fabricación del queso y de la caseína, después que se separa la cuajada. Es un líquido fluido, de color verdoso amarillento, turbio, de sabor fresco, débilmente dulce, de carácter ácido, con un contenido de nutrientes o extracto seco del $5.5 \%$ al $7 \%$ provenientes de la leche (Wikipedia, 2011).

Con la elaboración de este proyecto se aplicó un método microbiológico para la extracción de quitina a partir de desechos de crustáceos por fermentación ácido láctica, utilizando suero de leche como sustrato y azúcar como fuente de carbono.

\section{METODOLOGÍA}

\section{Material}

a) Caparazón de crustáceos

Se utilizaron $500 \mathrm{~g}$ de desecho de camarón triturado para cada ensayo (ver Fig. 1). Estos caparazones de camarón fueron suministrados por la Empresa Camarones de Nicaragua, S.A. (CAMANICA), actualmente PESCANOVA ALIMENTACIÓN, S.A. 


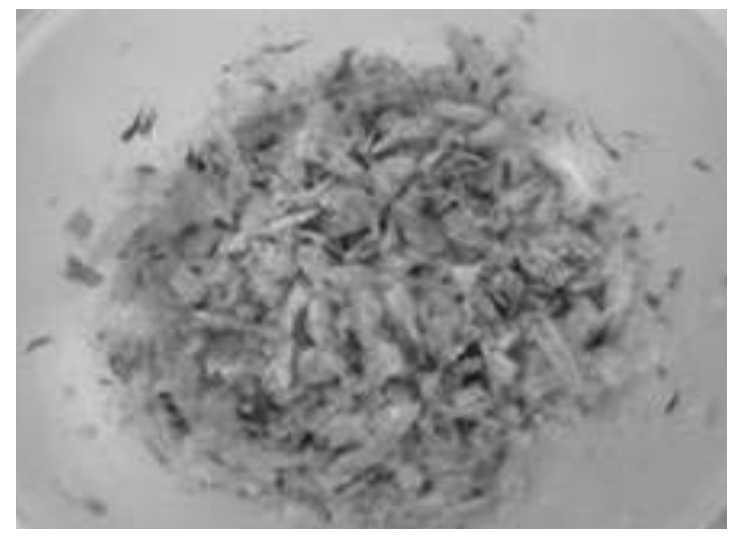

Fig. 1 Caparazón de camarón lavado y triturado.

b) Suero de leche

El suero lácteo (ver Fig. 2) fue obtenido por la coagulación en caliente $\left(\sim 45^{\circ} \mathrm{C}\right)$ de $5 \mathrm{~L}$ de leche pura y fresca con $0.1 \mathrm{~g}$ de pastilla de cuajo (que contiene principalmente la enzima renina o quimosina), a un $\mathrm{pH}$ de aproximadamente 6.0. Con ello, la leche se descompone en dos partes: una masa semisólida, compuesta de caseína y un líquido, que es el suero de leche. La caseína se separa del suero utilizando un colador y gasas estériles para remover las partículas finas. El suero fue posteriormente enriquecido con sacarosa al $10 \% \mathrm{p} / \mathrm{v}$. La lactosa, presente en el suero, y la sacarosa sirven como fuente de energía para que las bacterias ácido lácticas puedan producir el ácido orgánico que actuará sobre los desechos del crustáceo (Xu et al., 2008).

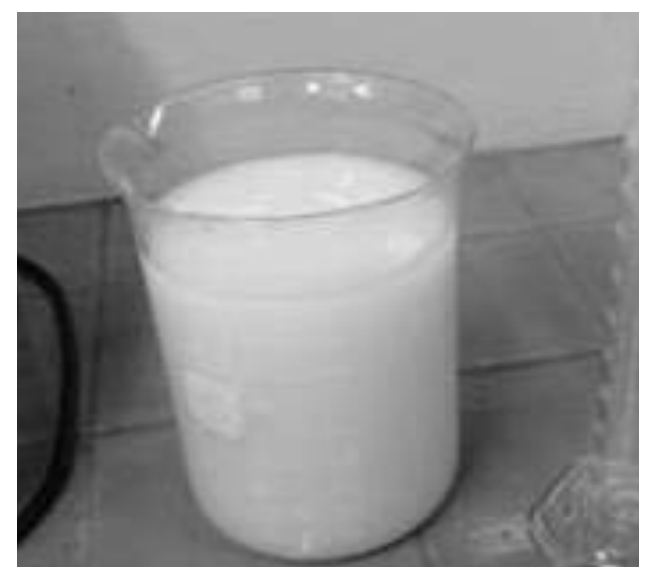

Fig. 2 Suero de leche obtenido a nivel de laboratorio.

\section{c) Reactivos}

Estos incluyen hidróxido de sodio $(\mathrm{NaOH})$ al 5 $\%$ e hipoclorito de sodio $(\mathrm{NaClO})$ al $0.38 \%$. Estos reactivos fueron preparados a partir de $\mathrm{NaOH}$ al $50 \%$ y $\mathrm{NaClO}$ al $12 \%$, los cuales fueron adquiridos en grado comercial.

\section{d) Quitina comercial de referencia}

La quitina de referencia fue adquirida en Jining Green Group Co. Ltd, Shandong, China.

\section{Método}

a) Proceso de extracción de quitina

El proceso a nivel de laboratorio involucró: (i) lavado, triturado y pesado del material; (ii) fermentación ácido láctica; (iii) procesamiento químico con $\mathrm{NaOH}$ al $5 \%$ y $\mathrm{NaClO}$ al $0.38 \%$, y (iv) secado del producto a una temperatura entre 45-50 ${ }^{\circ} \mathrm{C}$. La Fig. 3 muestra el diagrama del proceso.

La trituración se realizó en un procesador marca Oster para disminuir el tamaño del material con el propósito de promover la interacción entre las bacterias y el caparazón. De esta manera, se debilita la estructura del caparazón y se facilita la separación de la quitina, proteínas y calcio.

Por su parte, el proceso de fermentación se llevo a cabo en un reactor vertical de vidrio Pyrex de $4 \mathrm{~L}$ provisto de una canastilla cilíndrica de acero inoxidable concéntrico, donde se deposita el material, y de un agitador vertical con hélice de $500 \mathrm{rpm}$ (ver Fig. 4). Los desechos triturados fueron depositados en la canastilla y el suero lácteo fue vertido en el reactor ocupando (ambos) un volumen de aproximadamente el 75 $\%$ del reactor. El volumen total del suero enriquecido con sacarosa al $10 \% \mathrm{p} / \mathrm{v}$ fue de 2.25 L. La fermentación por lote se realizó por un período de 2 y 3 semanas a la temperatura ambiente. Cada 24 horas la mezcla era agitada por lapsos entre 10 y 30 minutos. La agitación es particularmente importante durante las primeras etapas de la fermentación ya que permite un buen contacto sólido-líquido, lo cual es esencial para la promoción de la disolución de calcio, y 
la consecuente evolución de $\mathrm{CO}_{2}$ que genera una atmósfera ideal que favorece a las bacterias del ácido láctico e inhibe a los organismos responsables de la putrefacción (Zakaria et al., 1998).

Alícuotas de $50 \mathrm{~mL}$ del licor fueron tomadas cada $24 \mathrm{~h}$ para determinar el $\mathrm{pH}$, el porcentaje de acidez total titulable y el contenido de calcio.
Para obtener un material de mejor calidad ( $\sin$ residuos de proteínas y pigmentos), se llevó a cabo la desproteinización con $\mathrm{NaOH}$ al $5 \%$ y blanqueo con $\mathrm{NaClO}$ al $0.38 \%$. El porcentaje de recuperación ( $\%$ R) se calculó mediante la siguiente ecuación:

$\% R=\frac{\text { Masa de Producto }(g)}{\text { Materia Prima inicial }(g)} \times 100$

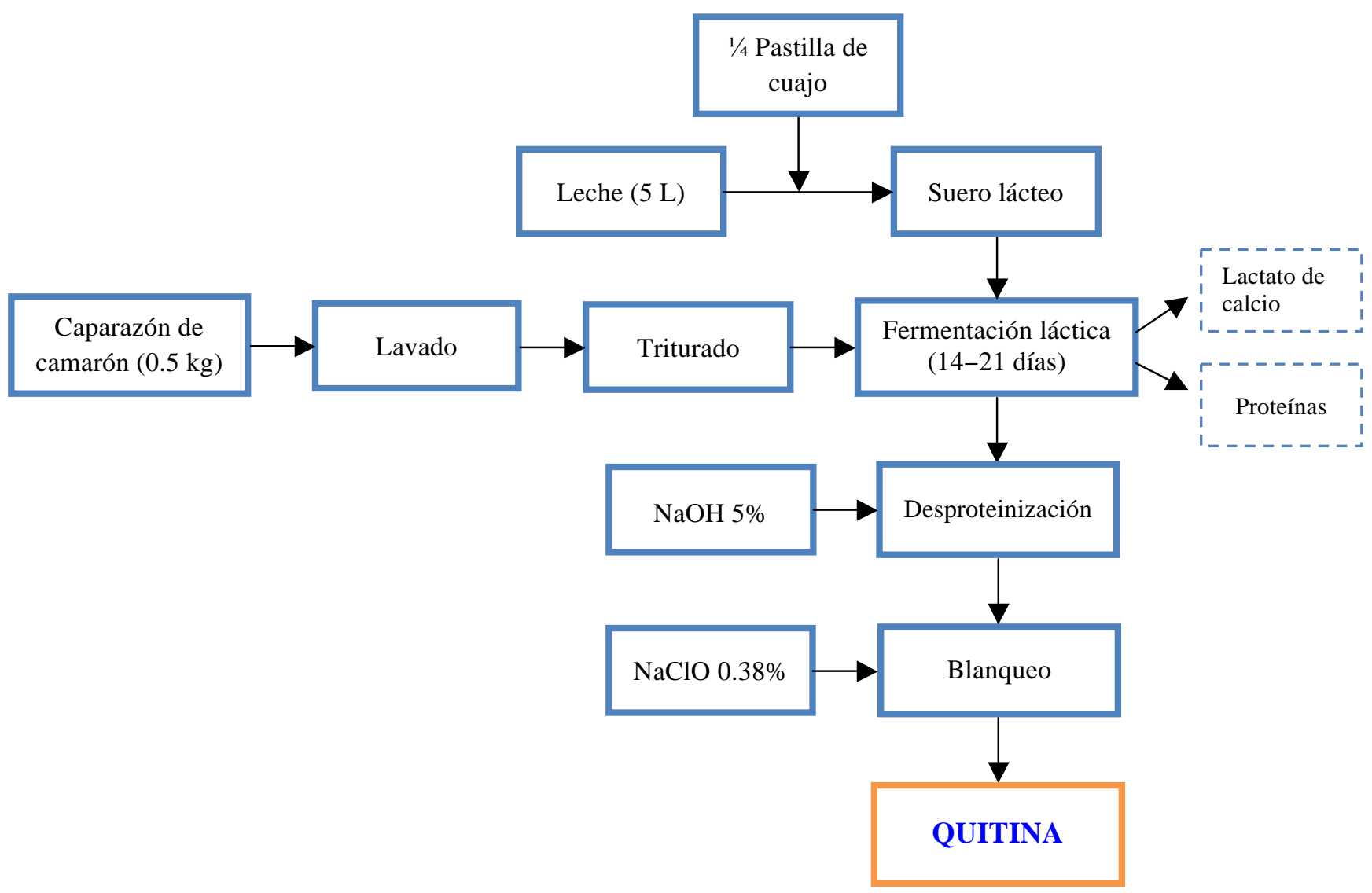

Fig. 3 Diagrama de bloque del proceso de obtención de quitina por fermentación láctica y tratamiento químico a partir de caparazón de camarón.

b) Análisis químico de las muestras

El análisis químico del licor recolectado del fermentador permitió evaluar la remoción de proteínas y minerales provenientes del caparazón de crustáceos y valorar el comportamiento de las bacterias durante la fermentación láctica.

Análisis de $\mathrm{pH}: \mathrm{El} \mathrm{pH}$ de las muestras se midió directamente con un pH-metro WTW-330i. El
pH-metro fue previamente calibrado con soluciones estándares de $\mathrm{pH}$ 4, 7 y 10.

Determinación del porcentaje de acidez total titulable (\% ATT): Para llevar a cabo el análisis se colocaron $2 \mathrm{~mL}$ del licor-muestra, $50 \mathrm{~mL}$ de agua destilada y 5 gotas de fenolftaleína en un matraz Erlenmeyer de $125 \mathrm{~mL}$. La muestra se tituló con una solución estandarizada de $\mathrm{NaOH}$ $0.1 \mathrm{M}$ hasta el viraje del indicador. 


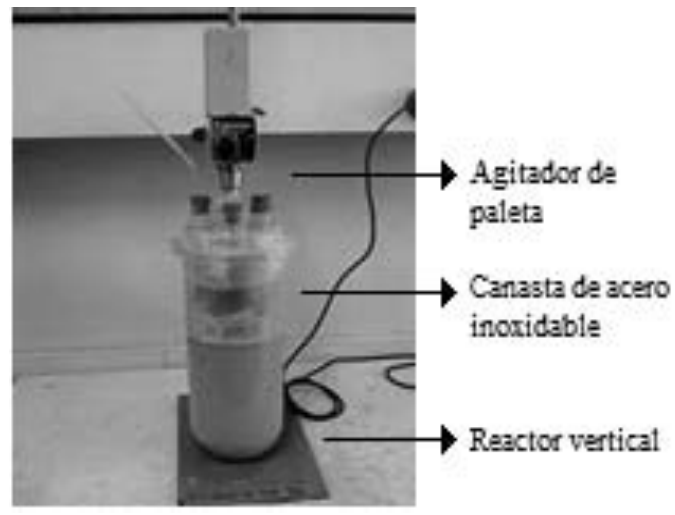

Fig. 4 Equipo de fermentación y sus componentes para la extracción de quitina.

Determinación de calcio: Las muestras fueron previamente acidificadas con $\mathrm{HNO}_{3}$ conc. para evitar la precipitación de $\mathrm{Ca}$. El análisis de calcio se determinó por absorción atómica, utilizando un Espectrómetro GBC modelo AAS932. El análisis abarcó la preparación de una curva de calibración con estándares de concentración conocida, los cuales fueron preparados por dilución con agua desionizada de una solución patrón de $1000 \mathrm{mg} / \mathrm{L}$ de Ca.

Espectro IR: Los espectros de la quitina producida y la quitina comercial fueron determinados en un Espectrofotómetro Bruker Optics ALPHA FT-IR.

\section{RESULTADOS Y DISCUSIÓN}

Obtención de quitina con un tiempo de fermentación de 2 semanas

En los desechos de crustáceos, la quitina está asociada con minerales de calcio (principalmente en forma de carbonatos), proteínas y pigmentos (principalmente astaxantina). Por lo tanto, para su recuperación es necesario remover estos materiales. En el método químico se usa $\mathrm{NaOH}$ para la remoción de proteínas (desproteinización) y $\mathrm{HCl}$ para remover los minerales de calcio (desmineralización).

En el método biológico, por su parte, esta función está a cargo de las bacterias (Lactobacillus) a través de la fermentación ácido láctica, la cual causa una reducción gradual del $\mathrm{pH}$ y un aumento continuo de la acidez total titulable.

En los gráficos de la Fig. 5 se presenta el comportamiento del $\mathrm{pH}$ y el porcentaje de acidez total titulable (\% ATT), que puede ser expresado como un porcentaje de ácido láctica, en función del tiempo de la fermentación ácido láctico. La Fig. 5(a) muestra que el $\mathrm{pH}$ fue decreciendo de 6.02 ( $\mathrm{pH}$ inicial del suero) hasta 3.68; mientras en la Fig. 5(b) se puede observar como incrementa el porcentaje de acidez total titulable con el tiempo, hasta alcanzar un valor de 2.79 $\%$.
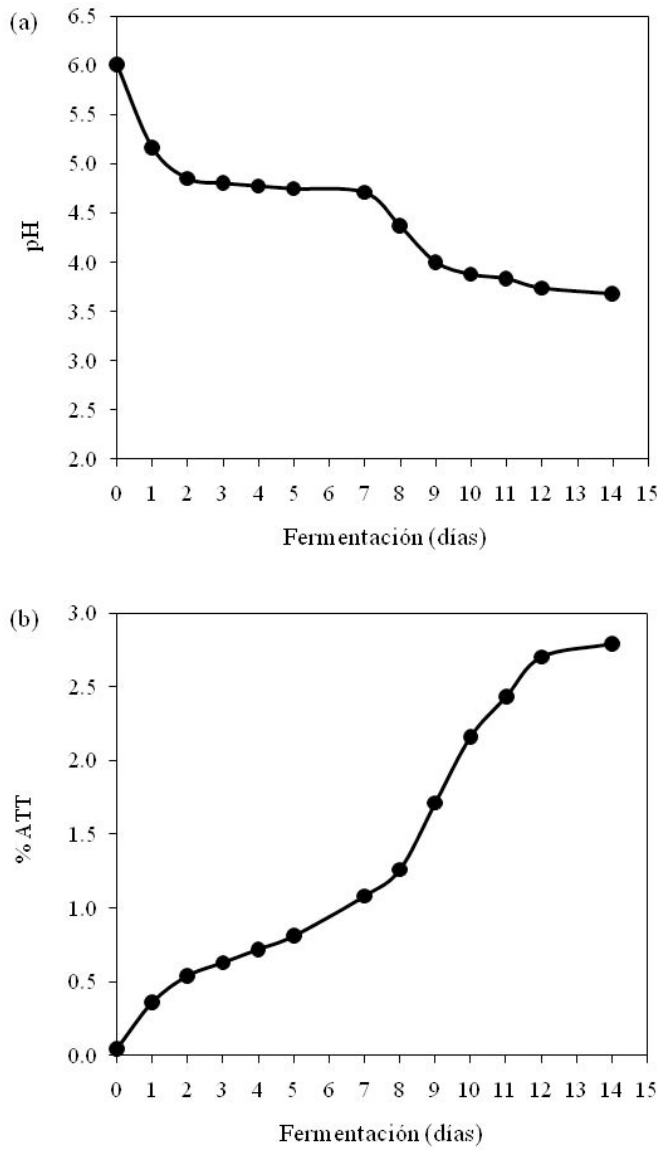

Fig. 5 Progreso de las variables de medición (a) pH y (b) porcentaje de acidez total titulable (\% ATT) durante el período de fermentación de dos semanas.

Según Beaney (2005), el aumento de la acidez resulta de la producción metabólica de ácido láctico a partir de la fuente de carbono, en este 
caso la sacarosa y la lactosa, lo cual indica la presencia de bacterias ácido láctica y su adecuado crecimiento.

Durante el proceso metabólico ocurre primero la separación de la molécula de sacarosa en glucosa y fructosa, y de la molécula de lactosa en glucosa y galactosa. En la glucólisis la célula transforma y oxida la glucosa para producir ácido pirúvico y posteriormente, el ácido láctico (ver Fig. 6), creando una condición de bajo pH que suprime el crecimiento de microorganismos no deseados Pseudomonas, Moraxella, Acinetobacter y Micrococcus (Rao et al., 2000; Shirai et al., 2001). De estos, las Pseudomonas son particularmente importantes por su alta actividad proteolítica ya que promueven la rápida putrefacción de los desechos de camarón (Shirai et al., 2001).

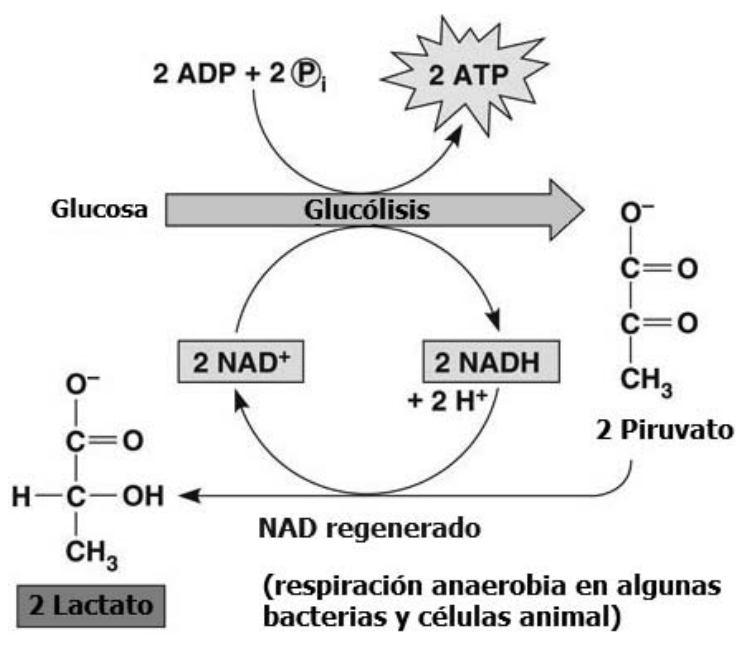

Fig. 6 Ruta metabólica de la fermentación ácido láctica para la producción de ácido láctico (Anderson, 2011).

Los resultados del análisis de calcio indicaron que se produjo una significante desmineralización del material. Los datos experimentales mostraron que hubo un aumento en la concentración de iones $\mathrm{Ca}^{2+}$ en la solución, de $1.21 \mathrm{~g} / \mathrm{L}$ en el suero (día 0) a $9.69 \mathrm{~g} / \mathrm{L}$ de Ca en el licor de fermentación al finalizar el proceso (día 14 del período de fermentación). El ácido láctico producido durante la fermentación láctica homofermentativa, reacciona con los minerales de calcio, los cuales se encuentran unidos a la quitina en el caparazón, produciendo lactato de calcio y alcanzando, de esta manera una remoción de aproximadamente el $80 \%$.

En la fermentación homoláctica una molécula de glucosa es convertida a dos moléculas de ácido láctico (Xu et al., 2008):

$$
\mathrm{C}_{6} \mathrm{H}_{12} \mathrm{O}_{6 \text { (soln) }} \rightarrow 2 \mathrm{CH}_{3} \mathrm{CHOHCOOH} \text { (soln) }
$$

y en la desmineralización, 2 moléculas de ácido láctico reaccionan con una molécula de carbonato de calcio:

$$
\begin{aligned}
& 2 \mathrm{CH}_{3} \mathrm{CHOHCOOH}(\text { soln })+\mathrm{CaCO}_{3(\mathrm{~s})} \rightarrow \\
& \mathrm{Ca}\left(\mathrm{CH}_{3} \mathrm{CHOHCOOH}\right)_{2(\text { soln })}+\mathrm{CO}_{2(\mathrm{~g})}+\mathrm{H}_{2} \mathrm{O}_{(\mathrm{l})}
\end{aligned}
$$

El lactato de calcio puede ser subsiguientemente recuperado del sistema, para su posterior utilización en la industria de alimentos, ya que es una de las sales orgánicas más utilizadas en bebidas claras por el aporte nutricional de calcio. Se puede usar en bebidas como leches fortificadas, leche de soya, néctares, jugos, etc. (Delta Enfoque, 2011).

La eficiencia en la remoción de calcio del material depende grandemente de la cantidad de fuente de carbono añadido (sacarosa y lactosa). De acuerdo a Shirai et al. (2001) un aumento en la concentración de glucosa causa un decrecimiento del $\mathrm{pH}$ debido al incremento en la producción de ácido láctico. Sin embargo, una concentración de glucosa mayor que un $10 \%$ puede provocar una fase de latencia prolongado debido a una disminución de la actividad del agua promovida por la alta concentración de azúcar en el sistema. Esto pueda causar una posible putrefacción debido a la competencia de los organismos de descomposición (Moraxella, Pseudomonas, Acinetobacter y Micrococcus) con las bacterias ácido láctico por el azúcar metabolizable.

La desproteinización, por su parte, es llevada a cabo por las enzimas peptidasas (antes conocidas como proteasas) las cuales se encuentran presentes de forma natural en el crustáceo. Estas enzimas son activadas a bajo $\mathrm{pH}$ y actúan rompiendo los enlaces peptídicos de las proteínas, provocando la hidrólisis y dando lugar a la producción de licor (Shirai et al., 
1997). Al finalizar la etapa de fermentación (14 días) se pudo apreciar que el producto aun contenía restos de pigmentos y restos proteicos indicando que el proceso de desproteinización no fue completo (ver Fig. 7(a)).

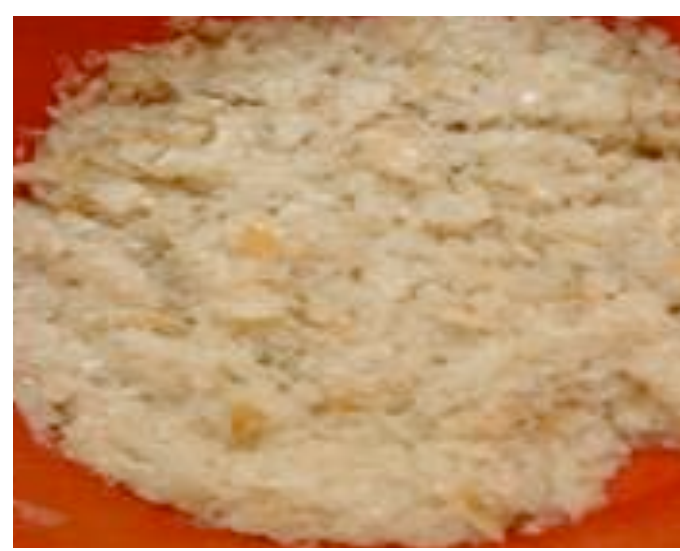

(a)

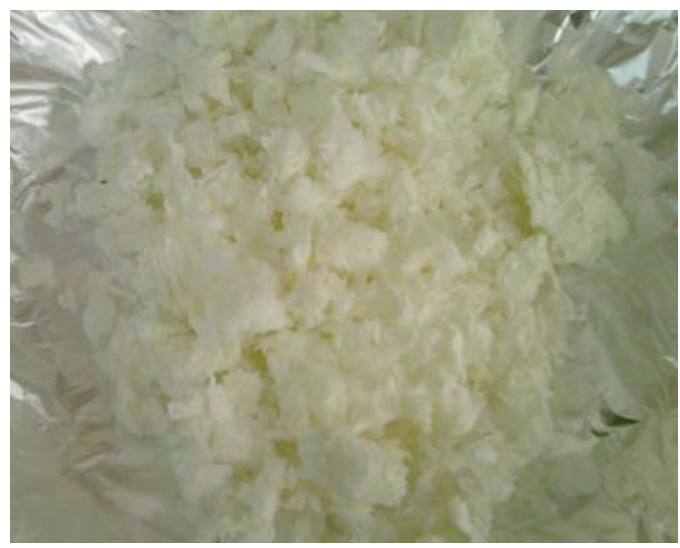

(b)

Fig. 7 Quitina producida (a) después del período de fermentación y (b) posterior al tratamiento con $\mathrm{NaOH}$ al $5 \%$ y $\mathrm{NaClO}$ al $0.38 \%$.

Para asegurar la completa remoción de las proteínas se adicionó $\mathrm{NaOH}$ al $5 \%$, en una proporción de $4 \mathrm{~L} / \mathrm{kg}$ de material, para conseguir el rompimiento del complejo quitina-proteína del caparazón. Así también, para remover los pigmentos del producto se adicionó $\mathrm{NaClO}$ al $0.38 \%$, en una proporción de $8 \mathrm{~L} / \mathrm{kg}$ de material, para remover los pigmentos. Al finalizar el procedimiento químico, la quitina obtenida tenía una apariencia suave al tacto, sin olor y sin pigmentación (Fig. 7(b)).
Obtención de quitina con tiempo de fermentación de 3 semanas

En la Fig. 8 se muestra los resultados de $\mathrm{pH}$ y porcentaje de acidez total titulable (\% ATT) en función del tiempo de fermentación en un período de 3 semanas. En estas pruebas también se observa una disminución del pH (de 5.75 a 3.74) y un incremento del \% ATT (de 0.09 a $3.06 \%$ ). La concentración de calcio en el licor alcanzó un valor de $10.85 \mathrm{~g} / \mathrm{L}$ a los 21 días de fermentación.
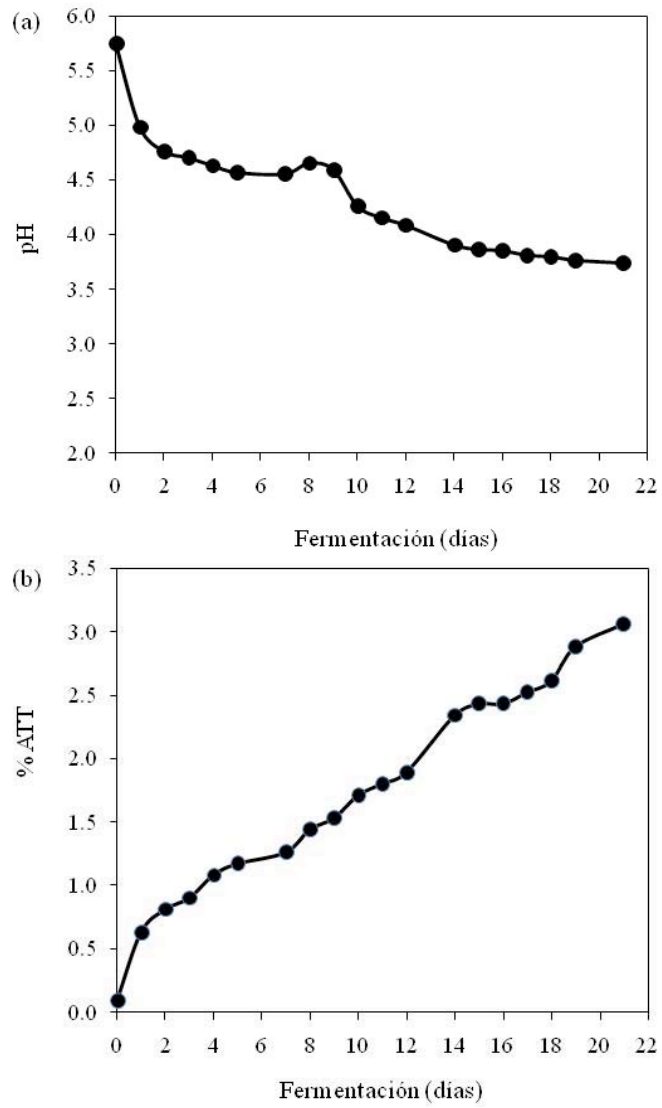

Fig. 8 Progreso de las variables de medición (a) pH y (b) porcentaje de acidez total titulable (\% ATT) durante la fermentación de tres semanas.

Los resultados también mostraron que a pesar de haber extendido el tiempo de fermentación, siempre persisten restos de proteínas y pigmentos, por lo que se hizo nuevamente necesario utilizar métodos químicos para completar la desproteinización y conseguir un blanqueo completo de la quitina producida. Al 
final del proceso se obtuvo una recuperación de quitina de aproximadamente el $85 \%$.

Al comparar los resultados de ambos experimentos se observa que el $\mathrm{pH}$ del licor en el proceso de fermentación de 3 semanas fue ligeramente mayor que el $\mathrm{pH}$ del licor de 2 semanas. Mientras que el \% ATT y el contenido de calcio en el licor en el período de 3 semanas son más altos (aproximadamente del $9.7 \%$ y $10.2 \%$, respectivamente) con relación al período de 2 semanas. Esto indica que al incrementar el tiempo de fermentación, incrementa la acidez en el sistema lo que permite una mayor remoción de minerales de calcio del caparazón de camarón.

Estos resultados concuerdan con aquellos obtenidos por $\mathrm{Xu}$ et al. (2008). Estos autores trabajaron en la purificación de la quitina de desechos de camarón usando Lactobacillus casei como inóculo y a diferentes concentraciones de glucosa, 2.7 y $5.4 \mathrm{~g}$ en base seca. Los resultados mostraron que al incrementar la cantidad de glucosa disminuye el $\mathrm{pH}$, obteniendo $\mathrm{pH}$ finales después de concluida la etapa de fermentación de 3.9 (con $2.7 \mathrm{~g}$ de glucosa) y 3.5 (con $5.4 \mathrm{~g}$ de glucosa) correspondiendo a una remoción de calcio de $80 \%$ y $72 \%$, respectivamente. Así también, notaron que la desproteinización no fue totalmente efectiva, alcanzado una eficiencia entre 40 y $85 \%$. Así también, similares resultados fueron obtenidos bajo nuestras condiciones de trabajo en comparación con aquellos obtenidos por Setyahadi (2007) que lograron una producción de ácido láctico de 1.09 $\%$ (v/v) y un $\mathrm{pH}$ de 4.15 después de 6 días de incubación a $37{ }^{\circ} \mathrm{C}$ usando MRS Agar (de Man, Rogosa y Sharpe) como medio de cultivo y melaza como fuente de carbono. Esto indica que el uso de sacarosa (azúcar blanca comercial) en vez de glucosa o melaza, puede ser efectiva como fuente de carbono para el crecimiento de las bacterias ácidas lácticas y la producción del ácido láctico.

Por otro lado, en un trabajo realizado por Rao et al. (2000) encontraron que uno de los factores críticos en la producción de quitina en cuanto a la eficiencia en la desproteinización y desmineralización del material es el $\mathrm{pH}$ inicial del licor de fermentación. De acuerdo a sus resultados, la adición de $1 \%$ de ácido acético $(\mathrm{p} / \mathrm{v})$ disminuye el $\mathrm{pH}$ del licor (de 8.0 a 6.0) lo cual evita la formación de microorganismos no deseados, incrementa la eficiencia de la desmineralización (de 44.1 a $67.5 \%$ ), pero disminuye ligeramente la eficiencia de la desproteinización (de 89.2 a $88.4 \%$ ). Esta tendencia es más evidente a medida que se incrementa la adición del porcentaje de ácido acético en el sistema. El uso de suero lácteo en nuestro trabajo permitió tener las condiciones de pH necesarios (entre 5.4-6) en la fermentación láctica, además del aporte de altos contenidos de lactosa como sustrato (Trujillo et al., 1998), alcanzar una buena eficiencia en la desmineralización y desproteinización del material de desecho. Sin embargo, como se mencionó anteriormente, mediante la sola utilización de la fermentación láctica no es posible recuperar la quitina con un buen grado de pureza. Por ello, Cira et al. (2002) trataron la quitina obtenida del proceso de fermentación con ácido (HCL 1-1.5 N) y álcali $(\mathrm{NaOH} 1.75$ $\mathrm{N})$ para la eliminación de minerales y proteínas.

\section{Análisis de espectros FTIR}

El espectro FTIR de la quitina producida (Fig. 9(a)), exhibe una banda intensa y ancha a 3500 $\mathrm{cm}^{-1}$ asociada al grupo $\mathrm{OH}$ y presenta una absorción en la región de $1730 \mathrm{~cm}^{-1}$ relacionada a la vibración de tensión del enlace $\mathrm{C}=\mathrm{O}$. Además se observan fuertes bandas de absorción a 2900 y $1450 \mathrm{~cm}^{-1}$ que corresponden a las vibraciones de tensión y deformación del enlace C-H y una banda a $1650 \mathrm{~cm}^{-1}$ asociada con la amida. Esta banda muestra dos picos: uno que se atribuye al enlace de hidrógeno intermoleculares $\mathrm{CO} \cdots \mathrm{HN}$ a $1660 \mathrm{~cm}^{-1}$ y otro debido al enlace de hidrógeno intramolecular $\mathrm{CO} \cdot \mathrm{HOCH}_{2}$ a 1625 $\mathrm{cm}^{-1}$. Esta banda característica es usada para distinguir entre $\alpha$-quitina y la $\beta$-quitina, ya que en el caso de la $\beta$-quitina una sola banda puede ser observada a $1656 \mathrm{~cm}^{-1}$.

La comparación del espectro infrarrojo de la quitina obtenida con una quitina comercial, la cual fue usada como referencia (Fig. 9(b)) refleja un porcentaje de coeficiente de 
correlación del $95 \%$. La figura muestra que los espectros FTIR de ambos materiales son muy parecidos en lo que respecta a la posición de las bandas de los principales grupos de la quitina.
Este hecho indica que utilizando un procedimiento microbiológico-químico combinado, se obtiene una quitina con un buen grado de pureza.
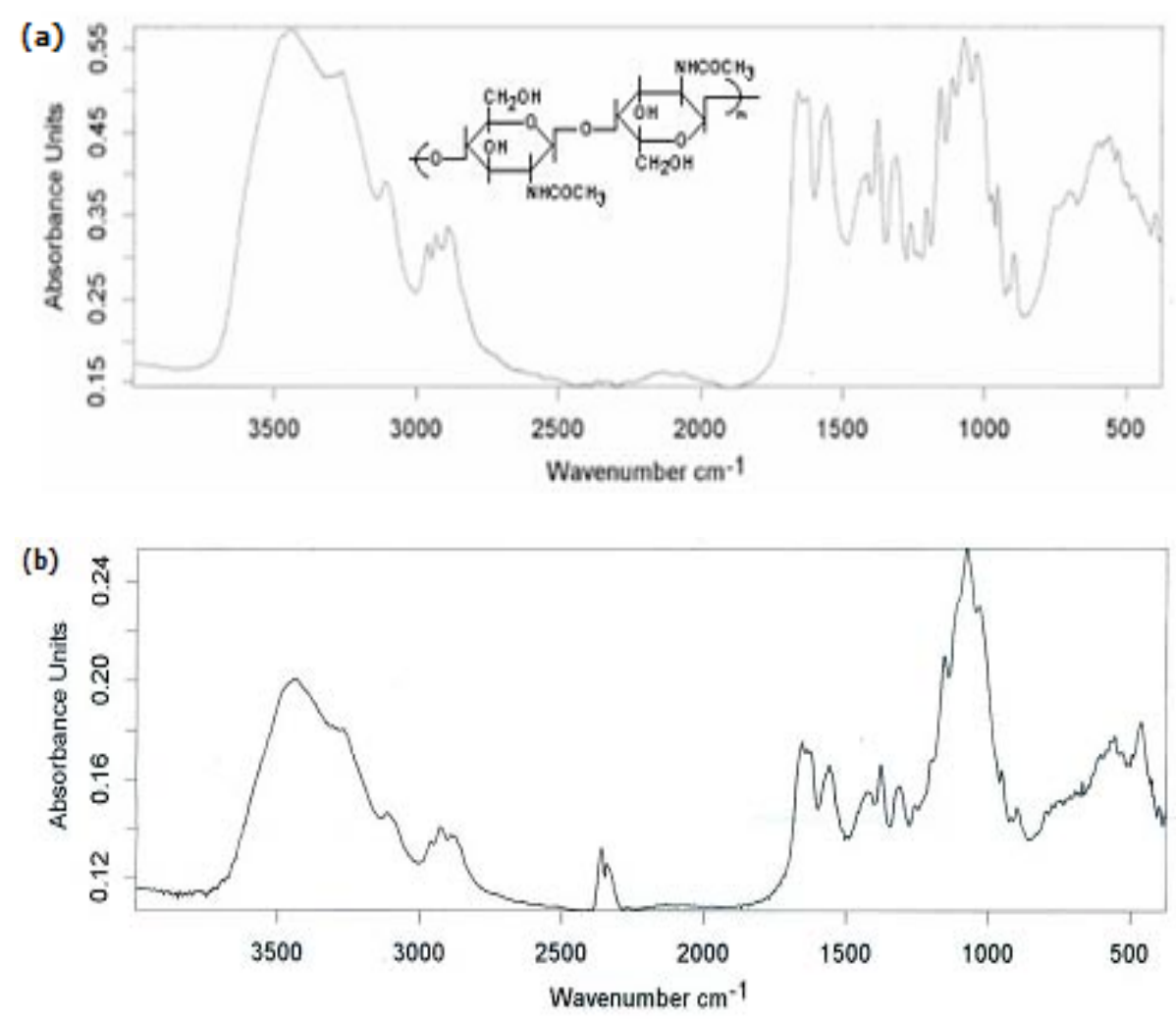

Fig. 9 Espectro FTIR de (a) la quitina obtenida por fermentación láctica combinado con procesamiento químico a partir de caparazón de camarón y (b) la quitina comercial usada de referencia.

\section{CONCLUSIONES}

El suero lácteo enriquecido con sacarosa al $10 \%$ $\mathrm{p} / \mathrm{v}$ resultó ser un buen sustrato para la fermentación ácido láctica, permitiendo la recuperación de subproductos y la conservación de los desechos. Con este estudio se combinó el método microbiológico y químico para obtener una alta recuperación de quitina de aproximadamente un $85 \%$, con un buen grado de pureza.

Así también, se logró reducir el uso de reactivos para la purificación del producto logrando así, un proceso más amigable al medio ambiente.

\section{AGRADECIMIENTOS}

Los autores agradecen a la Vice-Rectoría de I+D y al Programa UNI-Asdi-FIQ por el apoyo financiero para la realización de este estudio. Así también, a la empresa CAMANICA por el suministro de la materia prima.

\section{REFERENCIAS}

Beaney, P., Lizardi-Mendoza, J., \& Healy, M. (2005). Comparison of chitins produced by chemical and bioprocessing methods. Journal of Chemical Technology and Biotechnology, Vol. 80, No. 2, pp. 145-150. 
Carvalho, T., Nogueira, V., Melo, G., Pinheiro, P., Craveiro, A., \& Melo, V.M. (2009). Bioprocessing of crustacean shell waste to recovery chitin, proteins and pigments. En: Rustichelli, F., Caramella, C., Senel, S., \& Vaarum, K.M. (Eds.). Advances in chitin science, vol. XI (pp. 431-434). Venice, Italy: Polytechnic University of Marche.

Cira, L.A., Huerta, S., Hall, G.M., \& Shirai, K. (2002). Pilot scale lactic acid fermentation of shrimp wastes for chitin recovery. Process Biochemistry, Vol. 37, No. 12, pp. 1359-1366.

Harish, K.V., \& Tharanathan, R.N. (2007). Chitin/Chitosan modifications and their unlimited application potencial-an overview. Trends in Food Science \& Technology, Vol. 18, No. 3, pp. 117-131.

Hernández, D. \& Escorcia, D. (2009). Propuesta Técnica para la obtención de quitina a partir de caparazones de crustáceos a nivel de planta piloto. Tesis de Ingeniero Químico. Universidad Nacional de Ingeniería (UNI), Managua, Nicaragua.

López, A., García, M., \& Quintero, R. (2004). Biotecnología Alimentaria. México D.F., México: Editorial Limusa, S.A. de C.V.

Pastor de Abram, A. (2004). Quitina y Quitosano: obtención, caracterización y aplicaciones. Lima, Peru: Fondo Editorial de la Pontifica Universidad Católica del Peru.

Rao, M.S., Muñoz, J., \& Stevens, W.F. (2000). Critical factors in chitin production by fermentation of shrimp biowaste. Applied Microbiology and Biotechnology, Vol. 54, No. 6, pp. 808-813.

Setyahadi, S. (2007). Screening of lactic acid bacteria for the purpose of chitin recovery processing. Microbiology Indonesia, Vol. 1, No. 1, pp. 48-50.

Shirai, K., Guerrero, I., Huerta, S., Saucedo, G., Castillo, A., Gonzalez, R.O., \& Hall, G.M. (2001). Effect of initial glucose concentration and inoculation level of lactic acid bacteria in shrimp waste ensilation. Enzyme and Microbial Technology, Vol. 28, No. 4-5, pp. 446-452.

Shirai, K., Huerta, S., Saucedo, G., Rodríguez, G., \& Hall, G.M. (1997). Aspects in protein breakdown during the lactic acid fermentation. En: Domard, A., Roberts, G.A.F., \& Varum, K.M. (Eds.). Advances in chitin science, vol. II (pp. 56-63). Lyon, France: Jaques Andre Publisher.

Trujillo, M., Suárez, F., \& Gallego, D. (1998). Fermentación láctica en continuo a partir de suero dulce de leche desproteinizado. Revista Colombiana de Biotecnología, Vol. 1, No. 1, pp. 45-50.

Wikipedia (2011). Suero de leche. Wikipedia: la enciclopedia libre, disponible en: http://es.wikipedia.org/wiki/Suero de leche.

[Consulta: 31 Mayo de 2011].

Xu, Y., Gallert, C., \& Winter, J. (2008). Chitin purification from shrimp wastes by microbial deproteination and decalcification. Apply Microbiology and Biotechnology, Vol. 79, No. 4, pp. 687-697.

Zakaria, Z., Hall, G.M., \& Shama, G. (1998). Lactic acid fermentation of scampi waste in a rotating horizontal bioreactor for chitin recovery. Process Biochemistry, Vol. 33, No. 1, pp. 1-6.

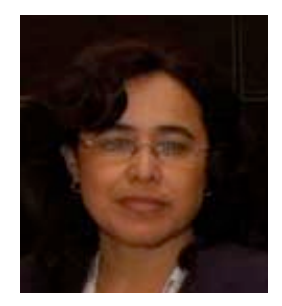

Martha Benavente se graduó de Licenciada en Química en la UNAN-León, en 1987. Obtuvo el grado de MSc en Ingeniería Química en la Universidad de Chile, en 2005 $y$ el grado de LicEng en Ingeniería Química en el Real Instituto Tecnológico (KTH), Suecia, en 2008. Sus intereses de investigación incluyen: procesamiento de biopolímeros a partir de crustáceos, remoción de metales pesados de aguas naturales y residuales. Profesor Titular, Facultad de Ingeniería Química, Universidad Nacional de Ingeniería, Nicaragua. 